\author{
III. - Pathology
}

\title{
A serological survey of the virus of the vomiting and wasting disease in piglets
}

\author{
P. VANNIER *, G. CHAPPUIS **, J.-L. LABADIE***, \\ L. RENAULT $* *$ et J. JOSSE * \\ * Direction de la Qualité, Services vélérinaires \\ Station de Pathologie porcine, B.P. $n^{\circ}$ 9, F 22440 Ploufragan \\ *: Département vétérinaire, I.F.F.A.-Mérieux, 254, rue Marcel-Mérieux, \\ F 69342 Lyon Cedex 2 \\ *** Société Sanders, I7, quai de l'Industrie, F 9I200 Athis-Mons
}

A serological study of the virus of vomiting and wasting disease in pigs was made using 2 groups of sera. In a first group 485 sow sera collected in 1977,1979 and 1980 in 41 farms, were studied. Twenty nine of these farms are distributed over the whole French territory, while the others are located in Brittany. On each farm, blood samples were collected from 15 p. 100 of the sows. In a second group of 534 sera collected from pigs aged less than 6 months, the variations in the level of antibodies according to the age of the pigs, were studied. The haemagglutination inhibition technique was used.

Among the 12 farms located in Brittany, the distribution of the level of antibodies in the sow sera was unequal in each herd. There was no correlation between the age of the sows and the level of antibodies in their sera. Among the 485 sow sera tested, 56.7 p. 100 contained antibodies. Only the sows in 3 herds of the 41 studied were not infected with this very common virus in pig populations. In the second study, in seemed that the level of antibodies varied with the age of the pigs. The antibodies detected in the sera of the pigs aged less than 3 months were probably maternal antibodies passively obtained via the colostrum.

When the pigs were 3 months old, the number of animais with sera free of antibodies was quite the same as the number of infected animals. Later, the number of infected animals was the double of the number of those without antibodies in their sera. The conditions of the spreading of the virus and of the appearance of the clinical cases in a herd are discussed.

\section{Infectious agents invclved in articular lesions of growing pigs}

\author{
Marylène KOBISCH \\ Direction de la Qualité, Services vétérinaires, \\ Station de Pathologie porcine, B.P. $n^{\prime \prime} 9, F 22440$ Ploufragan
}

In order to determine precisely the role of Mycoplasma hyorhinis in the development of articular lesions in the pigs, five different strains of Mycoplasma hyorhinis were tested during experimental infections in S.P.F. piglets.

Under the experimental conditions, there were differences in the expression of the pathogenicity of some Mycoplasma hyorhinis strains : one of them produced a slight pleuresia, while the others created articular lesions in the infected pigs comparable to those observed at the slaughter house in bacon pigs, often accompanied by lesions of the abdominal and thoracic serosae. 